\title{
Loss of generalist plant species and functional diversity decreases the robustness of a seed dispersal network
}

Vinicius A. G. Bastazini ${ }^{12}$, Vanderlei J. Debastiani², Bethânia O. Azambuja², Paulo R.

Guimarães Jr. ${ }^{3}$, Valério D. Pillar ${ }^{4}$

${ }^{1}$ Theoretical and Experimental Ecology Station, National Center for Scientific Research - Paul Sabatier University, 2 route du CNRS, 09200, Moulis, France

${ }^{2}$ Graduate Program in Ecology, Universidade Federal do Rio Grande do Sul, Porto Alegre, RS, 91501-970, Brazil.

${ }^{3}$ Departmento de Ecologia, Instituto de Biociências, Universidade de São Paulo, Rua do Matão, Travessa 14, no. 321, 05508-900, São Paulo, SP, Brazil.

${ }^{4}$ Department of Ecology, Universidade Federal do Rio Grande do Sul, Porto Alegre, RS, 91501-970, Brazil.

Summary: Understanding cascading effects of species loss has become a major challenge for ecologists. Traditionally, the robustness of ecological networks has been evaluated based on simulation studies where primary extinctions occur at random or as a function of species specialization, ignoring other important biological factors. Here, we estimate the robustness of a seed dispersal network from a grassland-forest mosaic in southern Brazil, simulating distinct scenarios of woody plant species extinction, including scenarios where species are eliminated based on their evolutionary and functional distinctiveness. Our results suggest that the network is more robust when species are eliminated based on their evolutionary uniqueness, followed by random extinctions, the extinction of the most specialist species, functional distinctiveness and, at last, when the most generalist species are sequentially eliminated. Our results provide important information for grassland-forest mosaic management, as they indicate that loss of generalist species and functional diversity makes the system more likely to collapse. 


\section{Introduction}

As we face the prospect of an unprecedented anthropogenic mass extinction, with species being lost at rates that are two or three orders of magnitude greater than the background rates from the geological record (Pimm et al. 2014, Ceballos et al. 2015), understanding and predicting the consequences of species extinction has become an urgent task for conservation scientists and practitioners (Vieira \& Almeida-Neto 2014, Ceballos et al. 2015). Most empirical studies examining the magnitude of biodiversity loss have usually ignored coextinction scenarios (Dunn et al. 2009, Vieira \& Almeida-Neto 2014), where the loss of one or more species may unleash a cascade of secondary extinctions, that may bring entire communities and ecosystems to collapse (Jackson et al. 2001, Fowler 2010, Colwell et al. 2012, Säterberg et al. 2013, Brodie et al. 2014, Donoso et al. 2017). Although the magnitude of coextinction process is still virtually unknown, given the difficulties of documenting it in natural systems (see for instance Dunn et al. 2009 and Moir et al. 2010), it has been suggested that these cascading effects should be more pervasive in some types of ecological interactions, such as parasitism and mutualism (Dunn et al. 2009, Kiers et al. 2010). The recent and rapid rise of Network Ecology - i.e., a field of research interested in understanding the function, structure, and evolution of ecological systems, using network models and analyses (Borrett et al. 2014) - has proved itself to be a powerful tool to describe the complexity of species interactions and their interdependence (Proulx et al. 2005, Pascual and Dunne 2006, Miranda et al. 2013), including their response to disturbance and cascading effects, such as coextinctions. Understanding what determines the robustness of mutualistic networks, i.e., the system's tolerance to secondary extinctions, is currently one of the main challenges faced by network ecologists (Solé \& Montoya 2001, Dunne et al. 2002, Memmot et al. 2004, Burgos et al. 2007, Rezende et al. 2007, Mello et al. 2011a, b, Pocock et al. 2012, Eklöf et al. 2013, Vieira et al. 2013, Astegiano et al. 2015). However, despite their importance, most studies trying to estimate the robustness of ecological networks have been traditionally based on scenarios that ignore other important ecological and evolutionary factors, such as species traits, associated to the likelihood of a species becoming extinct (e.g., Dunne et al. 2002, Memmot et al. 2004, Burgos et al. 2007, Pocock et al. 2012, but see Curtsdotter et al. 2011, Srinivasan et al. 2007, Vieira et al. 2013, Astegiano et al. 2015). In these studies, 
primary species extinctions are assumed to occur at random or as a consequence of species specialization (Solé \& Montoya 2001, Dunne et al. 2002, Memmot et al. 2004, Burgos et al. 2007, Rezende et al. 2007, Mello et al. 2011a, b, Pocock et al. 2012).

Species functional traits - behavioral, morphological or ecophysiological characteristics associated with biotic interactions, environmental conditions and/or ecosystem functions (Schmitz et al. 2015, Lefcheck et al. 2015) - play an important role in determining the structure and stability of ecological networks, as species traits can directly constrain the likelihood of interactions among individuals or species (Santamaría \& Rodríguez-Gironés 2007, Vizentin-Bugoni et al. 2014, Bastazini 2017) and the probability of extinction of a species (Purvis et al. 2000, Cardillo et al. 2005, 2008, Reynolds et al. 2005). Species traits imply that species are different in their ecological requirements and their effects on ecosystems. However, they are not equally different (Lefecheck et al. 2015), and some species are more likely to retain similar or "redundant" traits (Rosenfeld 2002, Pillar et al. 2013, Kang et al. 2015), conferring higher resistance and resilience to the system, in what is know as the "insurance effect of biodiversity" (Walker 1992, Pillar et al. 2013, Kang et al. 2015, Oliver et al. 2017). Thus, one might expect that the loss of more "distinct" and less redundant species in term of their traits might have a greater effect on how ecological networks respond to disturbances, as their role in the network can not be compensated by other species.

Plant-animal seed disperser interactions are an important mutualism that shapes both, ecological and evolutionary dynamics, through demographic processes that affect the fitness, reproduction success and the distribution of partner species (Snow 1971, Morton 1973, Herrera 1985, Jordano 2000, Correa et al. 2015). That these interactions are key drivers of biodiversity patterns is supported by the fact that only in the Tropics, up to $90 \%$ of all plant species rely on animals to disperse their seeds (Jordano 2000). Given their significance to maintain biodiversity and support ecosystem functioning, plant-disperser interactions are considered a crucial component in conservation and restoration strategies (Wunderle Jr. et al. 1997, Trakhtenbrot et al. 2005). Insofar, few studies have evaluated the robustness of seed dispersal systems (but see Mello et al. 2011a, b, Timóteo et al. 2016, 
Costa et al. 2018).

Seed dispersal networks also play a critical role in terrestrial ecotone zones, such as in grassland-forest ecotones, as animal seed disperser may help plant species to expand their distribution across phytophysiognomy boundaries, ultimately transforming the landscape (Jensen et al. 1986, Bossuyt et al. 1999, Fragoso et al. 2003, Azambuja 2009, Carlucci et al. 2011, Müller et al. 2012, Myster 2012). Grasslands are one of the major biomes of the planet, occupying an area equivalent to $31-43 \%$ of the land surface (Coupland 1979, White et al. 2000). Grasslands support high levels of biological diversity and endemism (White et al. 2000, Bond \& Parr 2010, Iganci et al. 2011, Parr et al. 2014) and are responsible for maintaining important ecosystem processes and economic activities, such as acting as carbon sinks, supporting livestock production and providing aesthetic and cultural values to local communities, especially pastoral societies (Coupland 1979, Breymer \& Van Dyne 1980, White et al. 2000, Hu et al. 2001, Overbeck et al. 2007, Curtin \& Western 2008, Parr et al. 2014, Henderson et al. 2016). Nonetheless, their conservation has been historically neglected by environmental policies (Overbeck et al. 2007, Bond \& Parr 2010, Parr et al. 2014) and despite their large area, and economic and environmental value, grasslands are among the most altered and threatened ecosystems of the planet (White et al. 2000, Bond \& Parr 2010, Henwood et al. 2010, Parr et al. 2014). In addition to anthropogenic threats, such as overgrazing, farm intensification and afforestation, temperate grasslands and savannas suffer from a natural process of forest expansion (Schwartz et al. 1996, Bowman et al. 2001, Bond \& Parr 2010, Overbeck et al. 2007, Müller et al. 2012). Although forest expansion is considered a threat to grassland conservation, this process creates a unique and useful scenario for ecological studies, as grassland-forest ecotones encompass a "mosaic of life forms" that share very distinct evolutionary origins and life histories (Luza et al. 2015) that compete for space and other resources. Seed dispersal networks, formed by woody plants and frugivores, are likely to be an important driver of spatial and temporal dynamics in grassland-forest mosaics, as seed dispersal of woody plants may accelerate the expansion of forest ecosystems (Azambuja 2009, Carlucci et al. 2011, Müller et al. 2012, Myster 2012). Thus, grassland-forest ecotones make an interesting case scenario to study simulated coextinctions, with important consequences to the development of conservation policies. For 
instance, if the goal of conservation efforts is to protect grasslands, these analyses can help us to identify species that should be managed in order to maintain grasslands. Also, if conservation efforts are aimed to maintain forest expansion or forest species, this sort of analyses can help us to identify species that should be of higher priority in conservation.

Here, we estimated the robustness of a seed dispersal network formed by woody plants and birds from a grassland-forest mosaic from southern Brazil. We simulated five distinct scenarios of woody plant species extinction, including scenarios where species are eliminated based on their evolutionary and functional distinctiveness. Our main hypothesis is that the loss of more functional distinct, and consequently less redundant, species should have a large effect on network robustness, as their role in the network can not be compensated by the remaining species. Given the lack of phylogenetic signal in traits in this network (Bastazini et al. 2017), we also expect that loss of phylogenetic distinct species will be less important. Although the role of bottom-up and top-down ecosystem regulation has been a much-debated topic for decades now (see for instance Hanley \& La Pierre 2015 and references therein), both theoretical and empirical evidence suggest that bottom-up dynamics are more prominent in shaping community dynamics in multitrophic scenarios (Goudard \& Loreau 2008, Scherber et al. 2010). Moreover, recent evidence suggests that plant extinctions may be more likely to trigger animal coextinctions than vice versa (Schleuning et al. 2016). Thus, we assumed a bottom-up regulation and simulated distinct scenarios of primary woody plant extinction and their effects on bird coextinctions.

\section{Material and Methods}

\section{Study system and seed dispersal network}

Our study system comprises a seed dispersal network from a forest-grassland mosaic located in southern Brazil (Azambuja 2009, Bastazini et al. 2017). The site (between $30^{\circ} 25^{\prime} 03^{\prime \prime} \mathrm{S} 52^{\circ} 21^{\prime} 37^{\prime \prime} \mathrm{W}$ and $30^{\circ} 25^{\prime} 54^{\prime \prime} \mathrm{S} 52^{\circ} 22^{\prime} 40^{\prime \prime} \mathrm{W}$ ) is characterized by gently rolling terrains, with altitudes ranging from 100 to $210 \mathrm{~m}$, and by a grassland matrix, which is manly used for cattle ranching (Azambuja 2009). Large forest patches occupy hill slopes and 
riparian areas and smaller shrubby and forest patches are sparsely distributed across the grassy landscape (Azambuja 2009, Bastazini et al. 2017). The average annual temperature is $16.5^{\circ} \mathrm{C}$ and the mean annual precipitation is $1504 \mathrm{~mm}$ (Instituto de Pesquisas Agronômicas 1989). For more details on the study region, please refer to Azambuja (2009).

We used data collected during a bird trapping study that lasted one year, between July 2007 and June 2008 (Azambuja 2009, Bastazini et al. 2017). Birds were captured in mist nets, which were set up for eight consecutive days every month in grasslands, approximately $1 \mathrm{~m}$ away from the border of forest patches, in order to optimize bird capture success. Captured birds were placed into fabric bags for 20 minutes, so their feces could be collected (Azambuja 2009, Bastazini et al. 2017). The seeds found in fecal samples were identified to the finest taxonomic resolution possible. Based on this information, we built a qualitative interaction matrix comprising of 22 woody plant species and 12 frugivorous bird species (Fig. 1). In a recent contribution, Bastazini et al. (2017) demonstrated that trait coupling between birds and plants is an important driver of the structure of this network. We used the phylogeny generated by Bastazini et al. (2017), based on the APG III megatree (R20100701.new; Angiosperm Phylogeny Group 2009), and the traits used in their analyses, two continuous (diaspore diameter and maximum plant height) and three categorical traits (aril presence, diaspore shape and color), to estimate the phylogenetic and functional distinctiveness index explained in detail below. Further information on the phylogeny and the functional traits used in our analyses can be found in Bastazini et al. (2017) and their Supplementary Material 4. 

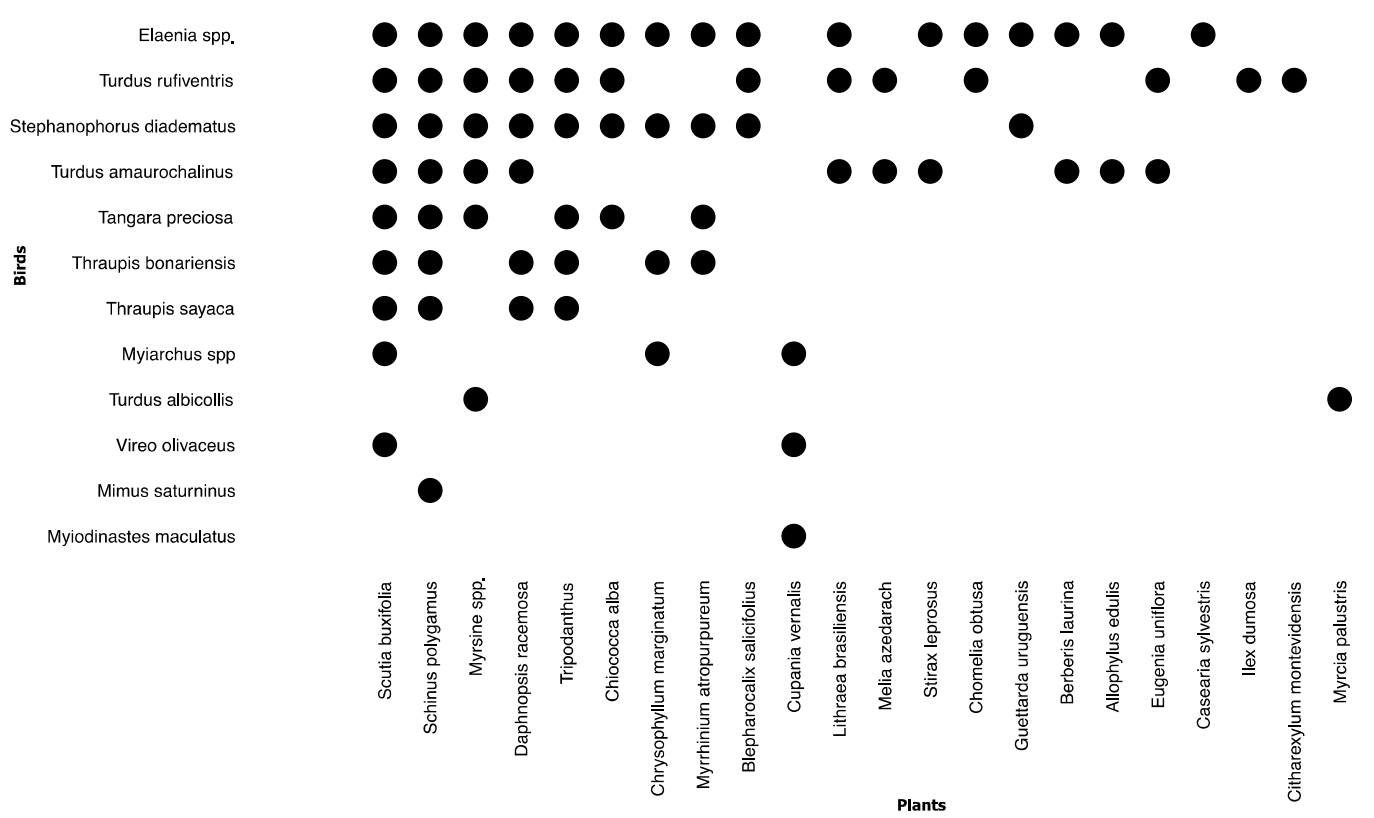

Fig. 1. Bi-adjacency matrix representing the seed dispersal network from a forest-grassland mosaic in southern Brazil.

\section{Numerical analyses}

We estimated the phylogenetic distinctiveness of each plant species, i.e., how isolated a species is on the phylogenetic tree, using the Fair Proportion metric, which is defined as the sum of all edge lengths between the species and the root of the phylogenetic tree, with each edge length being divided by the number of species in the cluster it subtends (Redding et al. 2008). We repeated the same procedure in order to estimate the functional distinctiveness of each species, i.e., how distinct a species is in terms of its functional traits, based on a functional dendrogram using plant traits. The functional dendrogram was built using Ward's sum of squares clustering procedure based on an Euclidean distance matrix calculated from species trait values (Legendre \& Legendre 2012).

Secondary extinctions of woody plants were simulated by five distinct elimination schemes. The first was based on i) random extinctions (using 1,000 simulations) and provided a baseline scenario to compare the effects of the other scenarios (Dunne et al. 2002, Memmot et al. 2004, Astegiano et al. 2015). The other scenarios considered species specialization in the seed dispersal network, either with ii) the most generalist (most connected plants) or iii) the most specialist (poorly connected plants) species disappearing 
first; iv) species eliminated based on their evolutionary distinctiveness; and v) based on species' functional distinctiveness. In both, iv) and v), most distinct species, either in terms of their traits of phylogenetic position are eliminated first. For each scenario we calculated network robustness $(R)$ defined as the area below the Attack Tolerance Curve (ATC; Albert \& Barabási 2002, Burgos et al. 2007), which represents the curve of the fraction of surviving bird species as a function of the eliminated plant species. $R$ values vary between 0 and 1 , where values closer to 1 indicate higher network robustness (Burgos et al. 2007).

All numerical simulations and analyses were performed in the $\mathrm{R}$ environment ( $\mathrm{R}$ Core Team 2012) and the code is available on Github (https://github.com/bastazini/Networks).

\section{Results}

Species were more variable in terms of their phylogenetic distinctiveness (range: 0.19 -0.48 ) than in terms of their functional distinctiveness (range: $0.19-0.25 ;$ Fig. 2). There was no correlation between both measures of distinctiveness (Pearson's $r=-0.015 ;$ P-value $=$ 0.94), which indicates that most unique species in the phylogenetic tree are not the most unique species in terms of their functional traits (Fig. 2). 

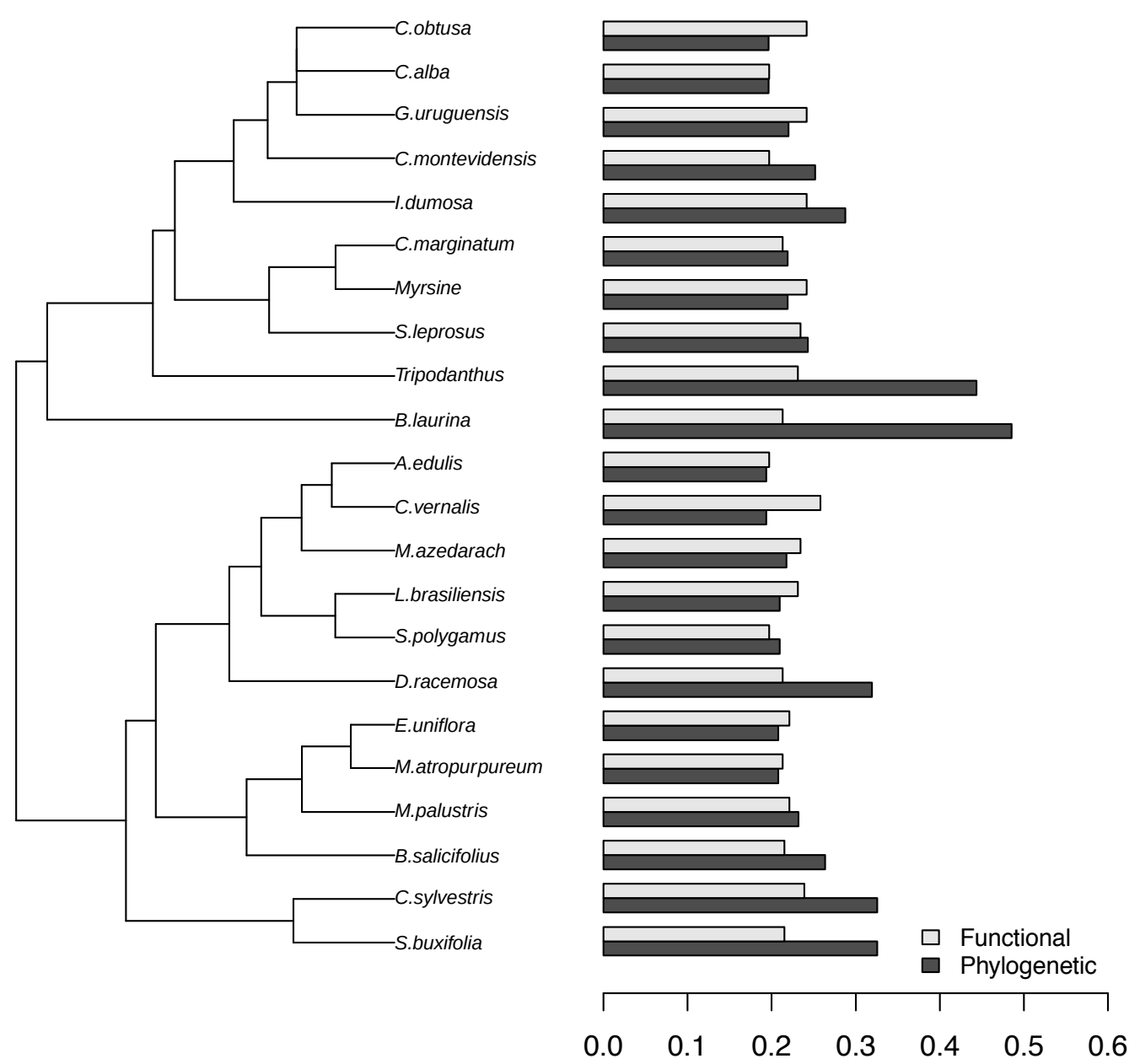

Distinctiveness

Fig. 2. Functional and phylogenetic distinctiveness of plant species, with the phylogeny plotted alongside, in a seed dispersal network from southern Brazil.

Considering all five scenarios, our seed dispersal network was likely to be very robust to the loss of woody plant species (average robustness considering all five simulated scenarios $=0.74 \pm S D=11.85)$. However, our simulations showed that distinct extinction scenarios have distinct effects on network robustness (Fig. 3). The loss of generalist species was more detrimental to network robustness, as the ATC of this scenario exhibited a very abrupt decline (Fig. 3 ii). The other scenarios showed a less steep response to the loss of plant species. Network robustness was higher when species were eliminated based on their evolutionary uniqueness, followed by random extinctions, the extinction of the most specialist species and functional distinctiveness (Fig. 3). 

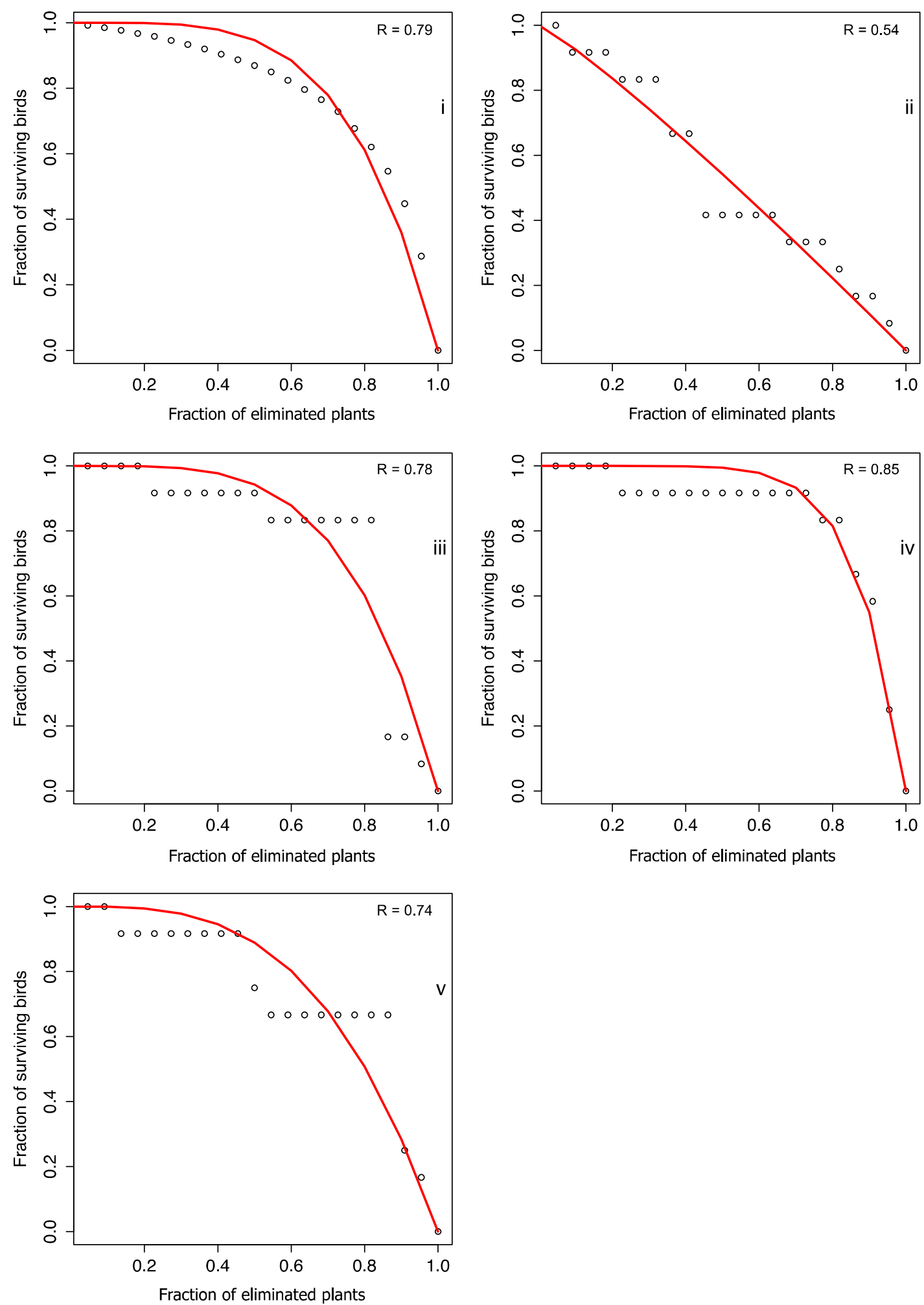

Fig. 3. Attack Tolerance Curves under different plant extinction sequences: i) random; extinctions based on species specialization either with ii) the most generalist (most connected plants) or iii) the most specialist (poorly connected plants) species disappearing first; iv) species evolutionary distinctiveness; v) species functional distinctiveness. 


\section{Discussion}

Over the past years, there has been a growing interest in trying to understand and estimate the consequences of coextinctions in ecological networks (e.g., Solé \& Montoya 2001, Dunne et al. 2002, Memmot et al. 2004, Burgos et al. 2007, Rezende et al. 2007, Mello et al. 2011a, b, Pocock et al. 2012). Insofar, most empirical evaluations have been based on scenarios where primary extinctions occur as a function of species specialization or as random events (Solé \& Montoya 2001, Dunne et al. 2002, Memmot et al. 2004, Burgos et al. 2007, Pocock et al 2012, Vieira et al. 2013). These scenarios may be unrealistic or offer a partial understanding of coextinction processes, as other ecological and evolutionary factors, such as body size and geographical range, influence the probability of a species becoming extinct (Purvis et al. 2000, Cardillo et al. 2005, 2008, Reynolds et al. 2005). Here, we provide further developments to coextinction analyses based on ATCs, combining functional and phylogenetic information, and show that the loss of generalist species has a larger effect on network robustness when compared to other extinction scenarios. Vieira et al. (2013) investigated the functional and phylogenetic consequences of random pollinator extinction in several pollination networks using a different metric to quantify functional and phylogenetic uniqueness. Their results suggest that there is an uncoupled response between functional and phylogenetic loss in mutualistic systems. Our study corroborates their findings, since our extinction scenarios based on functional and phylogenetic distinctiveness shows very different responses in terms of network robustness. As we predicted, given the lack of phylogenetic signal in plant traits in this seed dispersal network (Bastazini et al. 2017), plant functional and phylogenetic effects on bird species extinction were uncoupled, with the loss of phylogenetic distinct plant species having a lower impact on network robustness.

Despite this growing interest in coextinction and robustness analyses, studies focusing on seed dispersal networks are still scarce. Mello et al. (2011b) analyzed the robustness of 21 seed dispersal networks by simulating random extinctions of plants and frugivores (bats and birds). For plant-bird networks, they found that networks should be very robust to the loss of plant species, with a mean value of robustness $(R=0.75)$ similar to our result. Future studies are necessary to demonstrate whether seed dispersal networks are as 
robust as demonstrated by Mello et al. (2011b) and our own analyses. But as plant-seed disperser interactions are a system of low specialization (Herrera 1995, Muller-Landau \& Hardesty 2005, Donoso et al. 2017), high network robustness should be expected. The sensitiveness of dispersal networks to the primary extinction of plants or seed dispersers is still unclear. However Mello et al. (2011b) suggested that networks should be less robust when animal species are lost, Schleuning et al. (2016) argued that plant extinctions are more detrimental than animal extinctions in mutualistic networks. An important further step is to investigate the ability of species to replace their lost mutualistic partner. Experimental studies have suggested that rewiring, i.e., the re-arrangement of species interactions through time, is likely to promote higher resistance of seed dispersal networks (Timóteo et al. 2016, Costa et al. 2018). Nonetheless, we still lack a deep understanding of the underlying mechanisms driving rewiring in mutualistic networks, as different factors such as spatial-temporal cooccurrence, environmental gradients and species traits and abundance may determine the probability of species interactions (Danielson 1991, Jordano 2000, Vizentin-Bugoni et al. 2014, Schmitz et al. 2015, Bastazini et al. 2017). Although network rewiring models are likely to lead to more accurate predictions (Timóteo et al. 2016, Costa et al. 2018), not being able to correctly account for the mechanisms that determine the re-arrangement of species interactions or simulating unconstrained rewiring might lead to an overestimation of network robustness to secondary extinctions (Costa et al. 2018), which is undesirable from a conservation stand point. Nonetheless, we stress that although understanding the role of network rewiring is a critical question yet to be answered, our static and conservative approach provides valuable insights on the effects of eco-evolutionary mechanisms on network disassembly.

It is well recognized that generalist species, i.e., species with larger number of connections, play an important role in ecosystem functioning and stability (Memmot et al. 2004, Richmond et al. 2005, Gaston \& Fuller 2008, Poisot et al. 2013, Valiente-Banuet et al. 2015). González et al. (2010) suggested that generalist species have, at least, two important roles in pollination networks; the first obvious and intuitive role is that generalist species are able to interact with more species than specialist ones and the second role is the ability to connect otherwise unconnected sub-networks. Together, these two roles imply that generalist 
species are responsible for creating a more cohesive network. This cohesive pattern is likely to increment the ability of the system to respond to perturbations, and consequently increase its stability (Bascompte et al. 2003). Generalist and common species should receive special attention in conservation as even small declines in their populations may result in significant disruption of ecosystems (Gaston \& Fuller 2008). Our seed dispersal network comprises a very heterogeneous set of plant species in terms of phylogenetic history (15 taxonomic families), life history and functional groups, including trees (e.g., Scutia buxifolia, Cupania vernalis and Styrax leprosus), shrubs (Berberis laurina, Chomelia obtusa and Daphnopsis racemosa), vines (Chiococca alba) and hemiparasite species (Tripodanthus spp.). Among this diverse set of taxa, five of them are responsible for approximately $50 \%$ of all pairwise interactions, showing a larger number of connections: Scutia buxifolia, Schinus polygamus, Myrsine spp., Daphnopsis racemosa and Tripodanthus spp. Overall, these five taxa are characterized by low functional distinctiveness, with values lower than the median (except for Tripodanthus spp. and Myrsine spp.) and, except for Schinus polygamus, high phylogenetic distinctiveness (with values above the median). A common trait shared by these species is the size of their fruits, which is relatively small compared to the other species. As in other trophic interactions where predators have to swallow whole food items, fruit size is an important constraint in seed dispersal networks, and as a general rule, plants with large seeds and fruits tend to attract fewer animal species than plants with small fruits (Wheelwright 1985, Jordano 2000, Dehling et al. 2016, Donoso et al. 2017). Temporal availability and co-ocurrence with its seed dispersers have also been found to be important factors that increment the chance of a plant being consumed and dispersed by an animal (Jordano 2000). Among these five taxa, Myrsine spp. is the only one that produces fruits almost year-round (Azambuja 2009, Bastazini et al. 2017). Also, these well-connected species are among the taxa with larger temporal co-occurrence with the most bird species (Bastazini et al. 2017). Thus, small fruits and phenological patterns seemed to be a possible explanation to some structural patterns and the robustness of this seed dispersal network.

At last, we would like to underline the implications of our study to conservation policies, especially in southern Brazil. The conservation of grassland-forest mosaics of southern Brazil has been the focus of much debate in recent years (Overbeck et al., 2007, 
2013, Luza et al. 2014). As in other grassland ecosystems around the World, the grasslands of southern Brazil have experienced an increase in density of woody species that is drastically changing its physiognomy (Overbeck et al 2007, Müller et al. 2012). Forest expansion seems to be influenced by nucleation processes influenced by the presence of facilitating structures, such as rocky outcrops or isolated trees established in the grassland matrix, that act as perches for vertebrate dispersers and as safe sites for woody plants (Carlucci et al., 2011, Müller et al. 2012). Most of the generalist tree species that we found in our study are important species for woody plant encroachment of grasslands of southern Brazil (Carlucci et al. 2011, Müller et al. 2012). As we found the loss of generalist species and the loss of functional uniqueness are more detrimental to the robustness of seed dispersal networks of southern Brazil, these results could help to develop sounder strategies in species management and restoration of grassland-forest mosaics in southern Brazil.

In summary, our findings provide important information for forest and grassland management in southern Brazil, as they indicated that the sequential extinction of generalist woody plant species and functional plant diversity made the system more likely to collapse, whereas the loss of the most "unique" species, in terms of their evolutionary history, and specialist species had a smaller effect on network robustness. Moreover, despite its simplicity, our framework stresses the importance of considering distinct extinction scenarios and can help ecologists to understand and predict cascading effects in ecological systems.

\section{Acknowledgments}

We thank Andreas Kindel, André L. Luza, Danis Kiziridis, Kirsten Henderson, Paulo I. K. L. Prado, Rodrigo S. Bergamin and Sandra C. Muller and two anonymous reviewers for revising and providing valuable suggestions that greatly improved this manuscript. VAGB received support from CAPES (grant \#1002302), the TULIP Laboratory of Excellence (ANR10-LABX-41 and 394 ANR-11-IDEX-002-02) and from a Region Midi-Pyrenees project (CNRS 121090). VP received support from CNPq, Brazil (grant \# 307689/2014-0). PRG was supported by FAPESP (grant \#2009/54422-8) and CNPq. 


\section{References}

Angiosperm Phylogeny Group (2009) An update of the Angiosperm Phylogeny Group classification for the orders and families of flowering plants: APG III. Botanical Journal of the Linnean Society 161: 105-121.

Albert R, Barabási A (2002) Statistical mechanics of complex networks. Reviews of Modern Physics 74: 47-74.

Astegiano J, Massol F, Vidal, MM, Cheptou, PO, Guimarães Jr, PR (2015) The Robustness of Plant-Pollinator Assemblages: Linking Plant Interaction Patterns and Sensitivity to Pollinator Loss. PloS One 10(2): e0117243.

Azambuja, BO (2009) Relações entre aves dispersoras de sementes e manchas florestais em matriz campestre na Serra do Sudeste, RS. Ph. D. Thesis, Departament of Ecology, Federal University of Rio Grande do Sul, Rio Grande do Sul, Brazil.

Bascompte J, Jordano P, Melián CJ, Olesen JM (2003) The nested assembly of plant-animal mutualistic networks. Proceedings of the National Academy of Sciences 100: 93839387.

Bastazini VAG, Ferreira PMA, Azambuja BO, Casas G, Debastiani VJ, Guimaraes Jr. PR, Pillar VD (2017) Untangling the tangled bank: a novel method for partitioning the effects of phylogenies and traits on ecological networks. Evolutionary Biology 44:312-324.

Bond WJ, Parr CL (2010) Beyond the forest edge: ecology, diversity and conservation of the grassy biomes. Biological Conservation 143: 2395-2404.

Borrett SR, Moody J, Edelmann A (2014) The rise of network ecology: maps of the topic diversity and scientific collaboration. Ecological Modelling 293: 111-127.

Bossuyt B, Hermy M, Deckers J (1999). Migration of herbaceous plant species across ancient-recent forest ecotones in central Belgium. Journal of Ecology 87: 629-638. 
Bowman DMJS, Walsh A, Milne DJ (2001) Forest expansion and grassland contraction within a Eucalyptus savanna matrix between 1941 and 1994 at Litchfield National Park in the Australian monsoon tropics. Global Ecology \& Biogeography 10: 535-548.

Breymeyer Al, van Dyne GM (1980) Grasslands, systems analysis and man. Cambridge, UK: Cambridge University Press.

Brodie JF, Aslan CE, Rogers HS, Redford KH, Maron JL, Bronstein JL, Groves, CR (2014) Secondary extinctions of biodiversity. Trends in Ecology \& Evolution 29: 664-672.

Burgos E, Ceva H, Perazzo RPJ, Devoto M, Medan D, Zimmermann M, Delbue AM (2007) Why nestedness in mutualistic networks? Journal of Theoretical Biology 249: 307-313.

Cardillo M, Mace GM, Jones KE, Bielby J, Bininda-Emonds OR, Sechrest W, Orme CDL, Purvis, A (2005) Multiple causes of high extinction risk in large mammal species. Science 309: 1239-1241.

Cardillo M, Mace GM, Gittleman JL, Jones KE, Bielby J, Purvis A (2008) The predictability of extinction: biological and external correlates of decline in mammals. Proceedings of the Royal Society of London B: Biological Sciences 275: 1441-1448.

Carlucci MB, Duarte LDS, Pillar VD (2011) Nurse rocks influence forest expansion over native grassland in southern Brazil. Journal of Vegetation Science 22: 111-119.

Ceballos G, Ehrlich PR, Barnosky AD, García A, Pringle RM, Palmer, TM (2015) Accelerated modern human-induced species losses: Entering the sixth mass extinction. Science Advances 1: e1400253.

Colwell RK, Dunn RR, Harris NC (2012) Coextinction and persistence of dependent species in a changing world. Annual Review in Ecology, Evolution and Systematic 43: 183-203.

Correa SB, Costa-Pereira R, Fleming T, Goulding M, Anderson JT (2015) Neotropical fishfruit interactions: eco-evolutionary dynamics and conservation. Biological Reviews 90: $1263-1278$ 
Costa JM, Ramos JA, da Silva LP, Timóteo, S, Andrade P, Araújo PM, Carneiro C, Correia E, Cortez P, Felgueiras M, Godinho C, Lopes RJ, Matos C, Norte AC, Pereira PF, Rosa A, Heleno RH (2018) Rewiring of experimentally disturbed seed dispersal networks might lead to unexpected network configurations. Basic and Applied Ecology.

Coupland RT (ed) (1979) Grasslands ecosystems of the world: analysis of grasslands and their uses. Cambridge, UK: Cambridge University Press.

Curtin C, Western, D (2008) Grasslands, people, and conservation: Over-the-horizon learning exchanges between African and American pastoralists. Conservation biology 22: 870-877.

Curtsdotter A, Binzer A, Brose U, de Castro F, Ebenman B, Eklöf A, Riede JO, Thierry A, Rall, BC (2011) Robustness to secondary extinctions: comparing trait-based sequential deletions in static and dynamic food webs. Basic and Applied Ecology 12: 571-580.

Danielson BJ (1991) Communities in a landscape: The influence of habitat heterogeneity on the interactions between species. The American Naturalist 138: 1105-1120.

Dehling D, Jordano P, Schaefer H, Böhning-Gaese K, Schleuning M (2016) Morphology predicts species' functional roles and their degree of specialization in plant-frugivore interactions. Proceedings of the Royal Society of London B: Biological Sciences 283: 20152444.

Donoso I, Schleuning M, García D, Fründ J (2017) Defaunation effects on plant recruitment depend on size matching and size trade-offs in seed-dispersal networks. Proceedings of the Royal Society of London B: Biological Sciences 284: 20162664.

Dunn RR, Harris NC, Colwell RK, Koh LP, Sodhi NS (2009) The sixth mass coextinction: are most endangered species parasites and mutualists? Proceedings of the Royal Society of London B: Biological Sciences 276: 3037-3045.

Dunne JA, Williams RJ, Martinez ND (2002) Network structure and biodiversity loss in food webs: robustness increases with connectance. Ecology Letters 5: 558-567.

Eklöf A, Tang S, Allesina S (2013) Secondary extinctions in food webs: a Bayesian network 
approach. Methods in Ecology and Evolution 4(8): 760-770.

Fowler M (2010). Exticntion cascades and the distribution of species interactions. Oikos 119: 864-873.

Fragoso JMV, Silvius KM, Correa, JA (2003) Long-distance seed dispersal by tapirs increases seed survival and aggregates tropical trees. Ecology 84: 1998-2006.

Gaston, KJ, Fuller RA (2008) Commonness, population depletion and conservation biology. Trends in Ecology \& Evolution 23: 14-19.

González AMM, Dalsgaard B, Olesen JM (2010) Centrality measures and the importance of generalist species in pollination networks. Ecological Complexity 7(1): 36-43

Goudard A, Loreau M (2008) Nontrophic interactions, biodiversity, and ecosystem functioning: an interaction web model. The American Naturalist 171: 91-106

Hanley TC, La Pierre KJ (eds) (2015) Trophic Ecology: Bottom-up and Top-down Interactions across Aquatic and Terrestrial Systems. Cambridge,UK. Cambridge University Press.

Henderson KA, Reis M, Blanco CC, Pillar VDP, Printes RC, Bauch CT, Anand M (2016) Landowner perceptions of the value of natural forest and natural grassland in a mosaic ecosystem in southern Brazil. Sustainability Science 11: 321-330.

Henwood WD (2010) Toward a strategy for the conservation and protection of the world's temperate grasslands. Great Plains Research 20: 121-134.

Herrera, CM (1985) Determinants of plant-animal coevolution: the case of mutualistic dispersal of seeds by vertebrates. Oikos 44: 132-141.

Hu S, Chapin III FS, Firestone MK, Field CB, Chiariello NR (2001) Nitrogen limitation of microbial decomposition in a grassland under elevated CO2. Nature 409: 188-191.

Iganci JR, Heiden G, Miotto STS, Pennington, RT (2011) Campos de Cima da Serra: the Brazilian Subtropical Highland Grasslands show an unexpected level of plant endemism. Botanical Journal of the Linnean Society 167: 378-393. 
Instituto de Pesquisas Agronômicas (1989.) Atlas Agroclimático do Estado do Rio Grande do Sul. Porto Alegre, Brazil: Pallotti.

Jackson JB, Kirby MX, Berger WH, Bjorndal KA, Botsford LW, Bourque BJ, Bradbury RH et al. (2001) Historical overfishing and the recent collapse of coastal ecosystems. Science 293: 629-637.

Jensen TS, Nielsen, O F (1986). Rodents as seed dispersers in a heath-oak wood succession. Oecologia 70: 214-221.

Jordano P (2000) Fruits and frugivory. In: Seeds: The Ecology of Regeneration in Natural Plant Communities, ed Fenner M, pp125-165. Wallingford, UK:CABI Publishing.

Kang S, Ma W, Li FY, Zhang Q, Niu J, Ding Y, Han F et al. (2015) Functional Redundancy Instead of Species Redundancy Determines Community Stability in a Typical Steppe of Inner Mongolia. PLoS ONE 10:e0145605.

Kiers ET, Palmer TM, Ives AR, Bruno JF, Bronstein JL (2010) Mutualisms in a changing world: an evolutionary perspective Ecology Letters 13: 1459-1474.

Legendre P, Legendre LF (2012) Numerical ecology. Amsterdam, Netherlands : Elsevier.

Luza AL, Carlucci MB, Hartz SM, Duarte LD (2014) Moving from forest vs. grassland perspectives to an integrated view towards the conservation of forest-grassland mosaics. Natureza \& Conservação 12: 166-169.

Luza AL, Gonçalves GL, Hartz, SM (2015) Phylogenetic and morphological relationships between nonvolant small mammals reveal assembly processes at different spatial scales. Ecology and Evolution 5: 889-902.

Mello MAR, Marquitti FMD, Guimarães Jr PR, Kalko EKV, Jordano P, de Aguiar, MM (2011a) The missing part of seed dispersal networks: structure and robustness of bat-fruit interactions. PLoS One 6: e17395. 
Mello MAR, Marquitti FMD, Guimarães Jr PR, Kalko EKV, Jordano P, de Aguiar, MM (2011b)

The modularity of seed dispersal: differences in structure and robustness between batand bird-fruit networks. Oecologia 167: 131-140.

Memmott, J., Waser, N.M. \& Price, M.V. 2004. Tolerance of pollination networks to species extinctions. Proceedings of the Royal Society B 271: 2605-2611.

Miranda M, Parrini F, Dalerum F (2013) A categorization of recent network approaches to analyse trophic interactions. Methods in Ecology and Evolution 4: 897-905.

Moir ML, Vesk PA, Brennan KEC, Keith DA, Hughes L, McCarthy MA (2010) Current constraints and future directions in estimating coextinctions. Conservation Biology 24: 682-690.

Morton ES (1973) On the evolutionary advantages and disadvantages of fruit eating in tropical birds. The American Naturalist 107: 8-22.

Muller-Landau HC, Hardesty BD (2005) Seed dispersal of woody plants in tropical forests: concepts, examples and future directions. In: Biotic interactions in the tropics: Their role in the maintenance of species diversity, eds. Burslem DF, Pinard MA, Hartley SE, pp. 267-309. Cambridge, UK: Cambridge University Press.

Müller SC, Overbeck GE, Pfadenhauer J, Pillar VD (2012) Woody species patterns at forestgrassland boundaries in southern Brazil. Flora-Morphology, Distribution, Functional Ecology of Plants 207: 586-598.

Myster RW (2012) Ecotones between forest and grassland. New York, USA: Springer.

Oliver TH, Heard MS, Isaac NJB, Roy DB, Procter D, Eigenbrod F, Freckleton R, Hector A, Orme CDL, Petchey OL, Proênça V, Raffaelli D, Suttle KB, Mace GM, Martín-Lopez B, Woodcock BA, Bullock JM (2017). Biodiversity and Resilience of Ecosystem Functions. Trends in Ecology \& Evolution 30: 673-684. 
Overbeck GE, Müller SC, Fidelis A, Pfadenhauer J, Pillar VD, Blanco, CC, Boldrini, II, Both R, Forneck ED (2007). Brazil's neglected biome: The South Brazilian Campos. Perspectives in Plant Ecology, Evolution and Systematics 9: 101-116.

Overbeck GE, Hermann JM, Andrade BO, Boldrini II, Kiehl K, Kirmer A, Koch C, et al. (2013) Restoration ecology in Brazil-time to step out of the forest. Natureza \& Conservação 11: 92-95

Parr CL, Lehmann CER, Bond WJ, Hoffmann WA, Andersen AN (2014) Tropical grassy biomes: misunderstood, neglected, and under threat. Trends in Ecology and Evolution 29: $205-213$

Pascual M, Dunne JA (2006) Ecological networks: linking structure to dynamics in food webs. Oxford, UK: Oxford University Press.

Pillar VD, Blanco CC, Müller SC, Sosinski EE, Joner F, Duarte, LDS (2013) Functional redundancy and stability in plant communities. Journal of Vegetation Science 24: 963974.

Pimm SL, Jenkins CN, Abell R, Brooks TM, Gittleman JL, Joppa LN, Raven PH, Roberts CM, Sexton JO (2014) The biodiversity of species and their rates of extinction, distribution, and protection. Science 344: 1246752.

Pocock, MJ, Evans, DM, Memmott, J (2012) The robustness and restoration of a network of ecological networks. Science 335: 973-977.

Poisot T, Mouquet N, Gravel D (2013) Trophic complementarity drives the biodiversityecosystem functioning relationship in food webs. Ecology Letters 16: 853-861.

Proulx SR, Promislow DE, Phillips PC (2005) Network thinking in ecology and evolution. Trends in Ecology \& Evolution 20: 345-353.

Purvis A, Gittleman JL, Cowlishaw G, Mace GM (2000) Predicting extinction risk in declining species. Proceedings of the Royal Society of London B: Biological Sciences 267: 19471952. 
R Core Team (2012) R: A language and environment for statistical computing. R Foundation for Statistical Computing, Vienna, URL http://www.R-project.org/.

Redding DW, Hartmann K, Mimoto A, Bokal D, DeVos M, Mooers AØ (2008) Evolutionarily distinctive species often capture more phylogenetic diversity than expected. Journal of Theoretical Biology 251(4): 606-615.

Rezende EL, Lavabre JE, Guimarães PR, Jordano P, Bascompte J (2007) Non-random coextinctions in phylogenetically structured mutualistic networks. Nature 448: 925-928.

Reynolds JD, Dulvy NK, Goodwin NB, Hutchings JA (2005) Biology of extinction risk in marine fishes. Proceedings of the Royal Society of London B: Biological Sciences 272: 23372344.

Richmond CE, Breitburg DL, Rose KA (2005) The role of environmental generalist species in ecosystem function. Ecological Modelling 188: 279-295.

Rosenfeld JS (2002) Functional redundancy in ecology and conservation. Oikos 98: 156-162.

Santamaría L, Rodríguez-Gironés MA (2007) Linkage rules for plant-pollinator networks: trait complementarity or exploitation barriers? PLoS Bio 5: e31.

Säterberg T, Sellman S, Ebenman B (2013) High frequency of functional extinctions in ecological networks. Nature 499: 468-470.

Scherber C, Eisenhauer N, Weisser WW, Schmid B, Voigt W, Fischer M, Schulze E, et al. 2010. Bottom-up effects of plant diversity on multitrophic interactions in a biodiversity experiment. Nature 468: 553-556.

Schleuning M, Fründ J, Schweiger O, Welk E, Albrecht J, Albrecht M, Beil MN et al. (2016). Ecological networks are more sensitive to plant than to animal extinction under climate change. Nature Communications 7: 13965.

Schmitz OJ, Buchkowski R., Burghardt KT, Donihue C M (2015). Functional traits and traitmediated interactions: Connecting community-level interactions with ecosystem functioning. Advances in Ecological Research 52: 319-343. 
Schwartz D, Foresta H, Mariotti X, Balesdent J, Massimba JP, Girardin C (1996) Present dynamics of the savanna-forest boundary in the Congolese Mayombe: a pedological, botanical and isotopic (13C and 14C) study. Oecologia 106: 516-524.

Snow DW (1971) Evolutionary aspects of fruit-eating by birds. Ibis 113: 194-202.

Solé RV, Montoya, M (2001) Complexity and fragility in ecological networks. Proceedings of the Royal Society of London B: Biological Sciences 268: 2039-2045.

Srinivasan UT, Dunne JA, Harte J, Martinez ND (2007) Response of complex food webs to realistic extinction sequences. Ecology 88(3): 671-682.

Timóteo S, Ramos JA, Vaughan IP, Memmott J (2016) High resilience of seed dispersal webs highlited by the experimental removal of the dominant disperser. Current Biology 26: 910-915.

Trakhtenbrot A, Nathan R, Perry G, Richardson DM (2005) The importance of long-distance dispersal in biodiversity conservation. Diversity and Distributions 11: 173-181.

Valiente-Banuet A, Aizen MA, Alcántara JM, Arroyo J, Cocucci A, Galetti M, García MB, et al. (2015). Beyond species loss: the extinction of ecological interactions in a changing world. Functional Ecology 29: 299-307.

Vieira MC, Cianciaruso MV, Almeida-Neto M (2013) Plant-Pollinator coextinctions and the loss of plant functional and phylogenetic diversity. Plos One e 81242.

Vieira MC, Almeida-Neto M (2014) A simple stochastic model for complex coextinctions in mutualistic networks: robustness decreases with connectance. Ecology Letters 18: 144152.

Vizentin-Bugoni J, Maruyama PK, Sazima M (2014) Processes entangling interactions in communities: Forbidden links are more important than abundance in a hummingbirdplant network. Proceedings of the Royal Society of London B: Biological Sciences 281: 20132397.

Walker BH (1992) Biodiversity and ecological redundancy. Conservation Biology 6:18-23. 
Wheelwright NT (1985) Fruit-size, gape width, and the diets of fruit-eating birds. Ecology 66: 808-818.

White R, Murray S, Rohweder M (2000) Pilot Analysis of Global Ecosystems: Grasslands Ecosystems. Washington, USA: World Resource Institute.

Wunderle Jr JM (1997) The role of animal seed dispersal in accelerating native forest regeneration on degraded tropical lands. Forest Ecology and Management 99: 223-235. 